\title{
Jesse Shera no Brasil? contribuições para a biblioteconomia brasileira na década de 1950
}

Talita de Cássia Lima Paiva ${ }^{I}$

http://orcid.org/0000-0002-3332-8235

Diana Rocha da Silva II

http://orcid.org/0000-0003-4165-5495

I Universidade Federal do Maranhão, MA, Brasil.

Especialização em Biblioteconomia e Gestão de Bibliotecas Escolares pela UCAM.

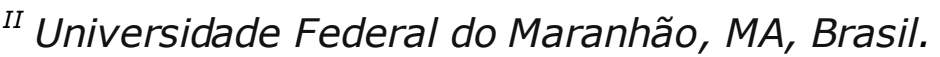

Doutora pelo Programa de Educação Escolar da Universidade Estadual Paulista Júlio de Mesquita.

http://dx.doi.org/10.1590/1981-5344/4295

Este estudo apresenta as contribuições de Jesse Hauk Shera para a configuração da Biblioteconomia no cenário brasileiro a partir da década de 1950, focalizando a análise no conteúdo e ideais disseminados no curso ministrado no Brasil. A pesquisa caracteriza-se como histórico-documental, destarte, foram contatadas instituições responsáveis pela guarda da memória da Biblioteconomia brasileira para obtenção de fontes primárias, entre estes periódicos da década de 1950. No conjunto de fontes secundárias estão trabalhos científicos de observadores da Biblioteconomia brasileira $e$ participantes deste momento histórico, que forneceram informações para reconstituir o período. Como resultado pode-se afirmar que Jesse Shera atuou no saber e fazer biblioteconômico da década de 1950 por meio de discussões e produções em torno do campo biblioteconômico. Sua influência é comprovada na 
educação de bibliotecários, em argumentações de dilemas e estudos na epistemologia da Biblioteconomia. Conclui-se que Shera foi e ainda é um expoente desta ciência e sua contribuição no Brasil foi significativa para uma teoria e prática com vieses norte-americano de pragmatismo e interação social. Sua produção bibliográfica se apresenta aberta a investigações no estudo sobre este teórico e no percurso da Biblioteconomia no país.

Palavras-chave: Biblioteconomia; Jesse Hauk Shera; Documentação.

\section{Jesse Shera in Brazil? contributions to Brazilian librarianship in the 1950s}

This study presents the contributions of Jesse Hauk Shera to the configuration of Librarianship in the Brazilian scenario from the 1950s, focusing on the analysis of the content and ideals disseminated in the course taught in Brazil. The research is characterized as historicaldocumentary, thus, institutions responsible for keeping the memory of Brazilian Librarianship were contacted in order to obtain primary sources, including periodicals from the 1950s. In the set of secondary sources are scientific works of observers of Brazilian Librarianship and participants of this historical moment, which provided information to reconstitute the period. As a result it can be stated that Jesse Shera acted in the knowledge and librarianship of the 1950s through discussions and productions around the librarianship field. His influence is evidenced in the education of librarians, in arguments of dilemmas and studies in the epistemology of librarianship. We conclude that Shera was and still is an exponent of this science and his contribution in Brazil was significant for a theory and practice with North American biases of pragmatism and social interaction. His bibliographic production is open to investigations on this theoretician and on the path of Librarianship in the country. 
Keywords: Librarianship; Jesse Hauk Shera; Documentation.

Recebido em 27.02.2020 Aceito em 08.09.2021

\section{Introdução}

A construção do conhecimento é um processo dinâmico e dialético, pois implica no diálogo entre diferentes perspectivas para a organização de um saber científico que responda aos dilemas sociais e que haja um retorno construtivo para a melhoria da ciência e da sociedade em que esta reflete. Particularmente, cada corrente de pensamento ou disciplina passa por este procedimento de identificação e reconhecimento social que ocorre por meio do desenvolvimento de conceitos, observações e expressões dos resultados mediante publicações, seminários, cursos.Porém, estas circunstâncias não surgem espontaneamente, mas das reflexões de intelectuais que fomentam a pesquisa e a ciência.

o conhecimento debatido por estes intelectuais é assimilado e disseminado por diversos meios de interpretação científicos e sociais. Significativa é a importância destes personagens para a construção do saber. No entanto, poucos estudos têm se concentrado na história destes produtores de cultura, ou seja, dos homens que pensaram e influenciaram determinadas gerações a utilizarem ou adotarem conceitos e práticas específicas visando consolidar filosofias emergentes e que, de certo modo, inspiraram e indicaram mudanças nas formas de pensar e de agir,a partir de certos objetos culturais.

Em pesquisa realizadas nas plataformas da Scientific Electronic Library Online (SciELO), Biblioteca Digital de Teses e Dissertações (BDTD), Portal do Instituto Brasileiro de Informação em Ciência e Tecnologia (IBICT), no Sistema Integrado de Bibliotecas Universidade de São Paulo (SIBI/USP), na Biblioteca Central da Universidade Federal do Maranhão (UFMA) e Google acadêmico, utilizando as palavras chaves "história da Biblioteconomia", "pioneiro da Biblioteconomia", "Paul Otlet ${ }^{1 ",}$ "Henri La Fontaine $^{2 ",}$ "Ranganathan", "Jesse Hauk Shera" e as suas possíveis

\footnotetext{
${ }^{1}$ Paul Marie Gislain Otlet (1868-1944) empresário belga, pesquisador e advogado, criador da CDU, juntamente com La Fontaine, e considerado um dos pais da Documentação.

${ }^{2}$ Henri Marie La Fontaine (1854-1943) jurista, políticos, belga e amigo de Paul Otlet, também considerado o pais da Documentação, dando visibilidade ao conceito.

${ }^{3}$ Shiyali Ramamrita Ranganathan, foi um matemático e bibliotecário indiano que desenvolveu o primeiro sistema de classificação analítico-sintético, a classificação dos dois pontos e as suas cinco leis da Biblioteconomia que são orientações em qualquer curso da área.
} 
combinações, foi possível verificar os seguintes resultados direcionados para os nomes de Paul Otlet, Henri La Fontaine, Ranganathan e Jesse Hauk Shera, com 1.870, 524, 1.710 e 62 respectivamente.

Jesse Hauk Shera, um dos teóricos com menor resultado na pesquisa, foi um bibliotecário atuante na Biblioteconomia e ainda é citado, porém, pouco estudado se comparado com outros intelectuais do campo Biblioteconômico. Doutor em Biblioteconomia pela Graduate Library School da Universidade de Chicago, atraído por temas como: epistemologia, história das bibliotecas, uso das tecnologias e estudioso da documentação; desenvolveu uma grande produção bibliográfica com um olhar técnico e social para a Biblioteconomia.

Seu pensamento reverberou por diferentes ciências e países, entre eles o Brasil, principalmente por se dedicar ao estudo da Documentação: tema desafiador, não apenas para Shera, mas também para os bibliotecários brasileiros na década de 1950. Nesta mesma época, foi convidado a ministrar um curso de Documentação e Organização Bibliográfica para capacitação dos profissionais da informação no país.

Sua visita ao Brasil foi amplamente divulgada à época, mas apesar de atualmente ser um acontecimento não muito comentado na literatura biblioteconômica brasileira, sua ministração repercutiu para a atualização, organização e estruturação desta ciência no país. Por isso, a análise das influências de Shera no Brasil possibilitou interpretações da conjuntura passada e, que nos permite compreender com mais profundidade a Biblioteconomia atual e as suas ressonâncias para a formação desse campo.

Dessa maneira, este artigo investiga quais as contribuições de Jesse Hauk Shera para o campo biblioteconômico brasileiro a partir da década de 1950, por meio da análise no conteúdo e ideais disseminados no curso ministrado no Brasil. Também procura contextualizar o campo Biblioteconômico brasileiro nesta década para se compreender o porquê do convite a Shera e não a outro teórico, além de apresentar o conteúdo do curso,para assim, apontar a influência de sua teoria e destas aulas para a estruturação da Biblioteconomia brasileira.

Tendo como escopo identificar as contribuições no diálogo, publicações, ações que se construíram entre os bibliotecários, igualmente entre as instituições em torno do tema abordado por Shera, no caso a documentação; este trabalho realizou-se pela pesquisa histórica, por intermédio de uma pesquisa bibliográfica e documental. As fontes primárias foram os jornais Diário da Noite (SP), Correio da Manhã (RJ), Diário de Notícias (RJ), Correio Paulistano (SP), Jornal do Brasil (RJ), Jornal do Commercio (RJ), Última Hora (RJ), Revista G. E. (BA), Revista do Livro (RJ), Tribuna da Imprensa (RJ), A Biblioteca (RJ), Diário de 
Pernambuco ( $P E)$, A Noite (RJ), que retratam a época, disponíveis na Hemeroteca Nacional Digital; a transcrição do curso ministrado sob guarda do IBICT e acessada pelo Programa de Comutação Bibliográfica $\left(\right.$ COMUT $\left.^{4}\right)$ e atas do Conselho Deliberativo do Conselho Nacional de Desenvolvimento Científico e Tecnológico (CNPq) acessadas pela Base de Dados Zenith do Museu de Astronomia e Ciências Afins (MAST ${ }^{5}$ ).

Para obter essas fontes foram contatadas as instituições IBICT, MAST que forneceram informações, e o CNPq, que não respondeu. $O$ diálogo teórico ocorreu com observadores que forneceram arcabouço teórico e contextual para a interpretação das informações encontradas e análise da conjuntura, entre estes, Sambaquy (1988) que participou e relatou momentos importante deste período; Oddone (2006) e Castro (2000), pesquisadores com rico material bibliográfico sobre a história da Biblioteconomia brasileira; bem como, Fonseca (1979) bibliotecário atuante que descreveu em periódicos e livros circunstâncias da área relevantes para análise, como a visita de Shera ao país; o próprio Shera (1957), para entender sua teoria e contrastar com os fatos recontados pelos teóricos dialogados e Bourdieu (1983) para se compreender e visualizar os dilemas das relações sociais envolvidas.

\section{A biblioteconomia brasileira em 1950}

A Biblioteconomia da década de 1950 era uma representação da sociedade brasileira. O Brasil, era um país pós Estado $\mathrm{Novo}^{6}$, que estava passando por transformações sociais e culturais, como a regularização do voto feminino, aumento no número de escolas públicas e universidades, etc. (SANT'ANNA, 1978).

Internacionalmente, o mundo estava se recuperando de seis anos de guerra mundial ao mesmo tempo em que floresciam os princípios capitalistas, avanços científicos e tecnológicos e mudanças culturais, como desenvolvimento dos meios de comunicação em massa que disseminavam o rock'n'roll e os modelos ideais de comportamento de uma sociedade visivelmente complexa inerente ao ser humano e ao sistema capitalista que estava se alastrando cada vez mais.Assim como os Estados Unidos da América e o estilo de vida americano que ampliavam seu domínio

\footnotetext{
${ }^{4}$ Programa de Comutação Bibliográfica (COMUT) foi criado em 1980, atualmente é de responsabilidade do IBICT e possibilita a obtenção de cópias de documentação científica disponíveis no acervo de bibliotecas brasileiras e internacionais cadastradas no programa.

${ }^{5}$ O Museu de Astronomia e Ciências Afins (MAST) localizado no Rio de Janeiro, possui a guarda de fontes históricas, entre atas, documentos administrativos e fotografias, etc., do CNPq da década de 1950 na sua Base de Dados Zenith, sendo um dos fundos contatados.

${ }^{6}$ O Estado Novo foi a última fase da Era Vargas, ocorreu durante 1937 a 1945. Foi um regime ditatorial baseado no nazifascismo europeu em prática na época.
} 
econômico e ideológico, sendo o Brasil um dos territórios alcançados em diferentes aspectos: político, econômico, cultural e social(KOSHIBA; PEREIRA, 2003).

Outra dimensão internacional a ser analisada desta década, além das divergências e realce de países ou correntes de pensamento foi o empenho para a pacificação e organização mundial. Muito da produção intelectual se perdeu durante a Segunda Guerra Mundial, sendo necessário a criação em 1945 da Organização das Nações Unidas para a Educação, a Ciência e a Cultura (UNESCO ${ }^{7}$ ) que desde a sua gênese, se interessou pela organização bibliográfica em nível mundial. É nesse contexto que a Biblioteconomia brasileira recebe interferência externa (SILVA, 1987).

Esta preocupação com a organização documental já havia sido manifestada em 1893, por Paul Otlet e Henri La Fontaine, através da fundação do Escritório Internacional de Bibliografia em Bruxelas ${ }^{8}$. Após conflitos, como a Primeira Guerra Mundial, essa ambição declinou, porém, novos conflitos impulsionaram a Unesco a retomar o discurso para uma organização bibliográfica em âmbito mundial, favorecendo a cooperação entre os países, a partir da implantação de centros bibliográficos que organizassem e disponibilizassem a informação e seus suportes para todo especialista que solicitasse.

O governo brasileiro da década de 1950 tinha preocupação com a documentação e a informação produzida no país, especialmente por terem sido potencializadas pela política Vargas do Estado Novo de centralização do poder; assim, estabeleceu-se instituições que auxiliavam na burocracia, na pesquisa científica, na abertura de bibliotecas e na metodização da bibliografia e documentação governamental e intelectual do país. Historicamente de 1937 a 1954, criou-se o Departamento Administrativo do Serviço Público (DASP) fundado em 1937, Fundação Getúlio Vargas (FGV), criada em 1944, Coordenação de Aperfeiçoamento de Pessoal de Nível Superior (CAPES) fundada em 1951 e o Conselho Nacional de Desenvolvimento Científico e Tecnológico (CNPq) em 1954(SILVA, 1987).

7 A UNESCO foi criada em 1945 após o término da Segunda Grande Guerra, conflito que desintegrou boa parte do conhecimento e documentação científica mundial. Após a guerra, a Unesco desempenhou forte papel na sistematização da bibliografia e documentação em nível mundial, implantando instituição em alguns países como México e Índia para a sistematização e disseminação da informação, sendo que os anos de 1950 significaram grandes passos para a Biblioteconomia.

8 O Escritório Internacional de Bibliografia em Bruxelas fundado em 1893 tinha por finalidade organizar um catálogo universal; em 1895 se tornaria no Instituto Internacional de Bibliografia (IIB), um marco biblioteconômico que disseminou os ideais utópicos e pacifistas de Otlet e La Fontaine que foram encerrados pela Primeira Guerra Mundial. 
Devido e esse sistema organizacional de informação e documentação, entre outras nações, o Brasil atraiu o olhar da UNESCO para investir na construção de um centro bibliográfico e de investimentos em bolsas aos bibliotecários para estudarem o funcionamento de centros de documentação no exterior. Portanto, em 27 de fevereiro de 1954 foi criado e instalado à Avenida General Justo, $171,3^{\circ}$ e $4^{\circ}$ andar, no Rio de Janeiro, o Instituto Brasileiro de Biblioteconomia e Documentação (IBBD), atual Instituto Brasileiro de Informação em Ciência e Tecnologia (IBICT); instituição desenvolvida a partir do planejamento do CNPq, mas com a colaboração da Fundação Getúlio Vargas e da Unesco, tendo

[...] por finalidade elaborar e divulgar informações bibliográficas; promover intercâmbio de documentação e de informações entre instituições nacionais e entre estas e instituições estrangeiras ou internacionais; estimular o desenvolvimento e aperfeiçoamento das bibliotecas científicas e técnicas do País. (BRASIL, 1954b, p. 2).

Correspondendo ao IBBD a função de circular e disponibilizar o conhecimento produzido pelas instituições e intelectuais no Brasil a quem solicitasse. Para realizar essa tarefa foi criada uma comissão"[...] integrada por: Joaquim da Costa Ribeiro, Octacílio Pinto Cordeiro de Souza e Mario Vianna Dias, representando o CNPq; Jorge Oscar de Mello Flores, Octacílio Silva Leal e Lydia de Queiroz Sambaquy, pela FGV." (SAMBAQUY, 1988, p. 34), inspirados pelos ideais otletianos e da documentação americana.

A documentação uma disciplina "[...] baseada nos ideais de acesso global às informações produzidas pelo ser humano [...]" (JUVÊNCIO, 2016, p.16) já era tema discutido fora do Brasil, mas no país ainda não era compreendido pela classe e nem dialogado com os documentalistas (ODDONE, 2006). E na década de 1950 o país necessitava se atualizar sobre o conhecimento produzido nas novas técnicas bibliotecárias. Por isso, ocorreu a ascendência desse conceito em debates no país, quando em 1957 esta palavra integrou o nome da Escola de Biblioteconomia da Faculdade Santa Úrsula, do Rio de Janeiro. Da mesma maneira"[...] em 1959 o congresso dos bibliotecários realizado em Salvador já se intitula $2^{\circ}$ Congresso Brasileiro de Biblioteconomia e Documentação [...]" (FONSECA, 1979, p. 42).

Paul Otlet e Henri La Fountaine são considerados os pais da Documentação e deram visibilidade ao seu conceito que somente viria a existir como disciplina a partir da primeira década do século XX e surgiu para corrigir a Bibliografia e a Biblioteconomia tradicionais, no controle e organização da produção gráfica (FONSECA, 1958a). Esta Documentação 
de matriz francófana, desenvolvida pela dupla belga, aplicada na Biblioteconomia americana adquiriu outros ideais, sendo elaborada uma corrente distinta, o pensamento bibliotecário americano, que teria forte influência no campo biblioteconômico brasileiro.

A Biblioteconomia americana, também chamada Biblioteconomia Especializada, teve suas bibliotecas provenientes da vontade popular e não por uma elite (MORAES, 1943). Esta é uma diferença entre a atuação humanitária americana, que visava ao acesso gratuito e aberto à população, e o viés humanista francês. A primeira, objetivava "Obrigar o povo a ler cada vez mais, levando o livro ao leitor, chamando sua atenção para os benefícios da leitura, com métodos publicitários iguais aos comerciais, é a preocupação do bibliotecário americano [...]" (MORAES, 1942, p. 198). Apesar desta especificidade este modelo se destacou por sua técnica e pelo foco na especialização e elaboração de dossiês temáticos, o que Lima (1999), em contrapartida, enfatizava que produziu uma conduta estéril, pois as atitudes dos bibliotecários se reproduziam em ações neutras e descontextualizadas da realidade social brasileira.

Pela configuração brasileira da década de 1950 americanizada e expansão desse modelo para diferentes âmbitos sociais, culturais e científicos, a Biblioteconomia brasileira não ficou imune, mas também adotou a corrente americana, que consolidou seu predomínio durante as décadas de 1940 a 1960 (CASTRO, 2000). Tendo a deficiência sobre a temática Documentação e o modelo americano hegemônico no país, o IBBD como organização para capacitar os bibliotecários brasileiros, coordenou cursos para atualizar os profissionais e modernizar as bibliotecas no Brasil inspirado por estes paradigmas.

Um dos cursos intitulado Documentação e Organização Bibliográfica foi ministrado por Jesse Hauk Shera. Este intelectual já era considerado um dos expoentes da Biblioteconomia no âmbito internacional.Era um dos nomes mais requisitados para representar o pensamento norte-americano em congressos sobre Documentação. Por sua forte atuação e competência sobre essas temáticas foi indicado para ministrar cursos de atualização para os profissionais da área. O primeiro foi realizado durante a sua vinda ao Rio de Janeiro nos dias 11 de agosto a 12 de setembro de 1957. Sua visita foi anunciada no Boletim do IBBD (MOURA, 1957), assim como nos periódicos cariocas Jornal do Brasil, Correio da Manhã, Diário de Noticiais, Diário Carioca, A Noite, Jornal do Commercio, Última Hora. O professor realizou o curso e atividades desta mesma natureza em outros estados, como palestra na Bahia e em São Paulo visita a Associação Paulista de Biblioteconomia.

Na pesquisa realizada não foi possível localizar outros estudos que revelassem os desdobramentos ou detalhes destes acontecimentos citados 
acima,que expressem uma maneira de conhecer 0 percurso da Biblioteconomia e Documentação no país e também dos expoentes internacionais do campo biblioteconômico. No entanto, foram espaços de forte atuação deste intelectual na Biblioteconomia brasileira, conforme análise a seguir.

\section{Curso de documentação e organização bibliográfica}

Produzir ciência não é fácil e exige critérios rigorosos de comprovação e veracidade. De acordo com Demo (2000, p. 22) "[...] no campo científico é sempre mais fácil apontarmos o que as coisas não são, razão pela qual podemos começar dizendo o que o conhecimento científico não é." Como comentado na introdução, a institucionalização de uma ciência envolve acordos e conflitos que não são isentos a relações de poder, mas são campos nos quais "[...] estruturados de posições (ou de postos), cujas propriedades dependem das posições nestes espaços, podendo ser analisados independentemente das características de seus ocupantes [...]". (BOURDIEU, 1983, p. 89).

Assim, a oficialização do curso Documentação e Organização Bibliográfica é mais do que um espaço para a instrução de um conhecimento específico.Trata-se de dar respostas a embates teóricos mais extensos, como as divergências entre as correntes biblioteconômicas francesa e americana; bem como o estabelecimento da Documentação e Ciência da Informação no Brasil (CASTRO, 2000; FONSECA, 1979).

Este curso realizado a convite do IBBD e do CNPq, patrocinado pela Coordenação de Aperfeiçoamento de Pessoal de Nível Superior (CAPES), teve início no dia 12 de agosto de 1957. Era composto por 21 preleções. A ementa foi divulgada no Jornal do Brasil (RJ), Correio da Manhã (RJ), Diário de Notícias (RJ), Diário Carioca (RJ), A Noite (RJ), Última Hora (RJ), e seguiu o seguinte programa (CHEGARÁ..., 1957; DEÃO..., 1957a, O DEÃO..., 1957;):

Quadro 1-Programa do Curso Documentação e Organização Bibliográfica 


\begin{tabular}{|c|c|c|}
\hline \multicolumn{3}{|c|}{ Curso Docume ntação e Organização Bibliográfica ${ }^{9}$} \\
\hline DATA & TEMA DA AULA & OBSERVAÇÃO \\
\hline 12.08 .1957 & $\begin{array}{l}\text { 1. Documentação, suas finalidades e } \\
\text { características, suas relações com os processos da } \\
\text { comunicação de ideias e com a Biblioteconomia. }\end{array}$ & Resumo \\
\hline $\begin{array}{l}\text { Não } \\
\text { datada }\end{array}$ & 2. Forma Bibliográfica. & $\begin{array}{l}\text { Apresentada no mesmo } \\
\text { dia da aula } n^{\circ} 3 \text {. }\end{array}$ \\
\hline $\begin{array}{l}\text { Não } \\
\text { datada }\end{array}$ & $\begin{array}{l}\text { 3. Teoria geral da bibliografia e sua relação com } \\
\text { as práticas biblio gráficas da documentação. }\end{array}$ & $\begin{array}{l}\text { Apresentada no mesmo } \\
\text { dia da aula } n^{\circ} 2 \text {. }\end{array}$ \\
\hline 19.08.1957 & $\begin{array}{l}\text { 4. Tipos de organização bibliográficas - o índice, } \\
\text { o catalo go, o "abstract", o ensaio bibliográfico. }\end{array}$ & \\
\hline 20.08 .1957 & $\begin{array}{l}\text { 5. Problemas de indexação, "Abstracting”, e } \\
\text { existentes na preparação de ensaios } \\
\text { bibliográficos. }\end{array}$ & \\
\hline 21.08 .1957 & 6. Organização das publicações - classificação. & \\
\hline 21.08 .1957 & $\begin{array}{l}\text { 7. Teoria da classificação - Consideração } \\
\text { histórica. }\end{array}$ & \\
\hline $\begin{array}{l}\text { Não } \\
\text { datada }\end{array}$ & 8. Sistema moderno de classificação. & $\begin{array}{l}\text { Dividido em parte I e } \\
\text { parte II }\end{array}$ \\
\hline $\begin{array}{c}\text { Não } \\
\text { datada }\end{array}$ & $\begin{array}{l}\text { 9. Outros métodos de localização e } \\
\text { sistematização das informações. }\end{array}$ & \\
\hline \multirow{2}{*}{$\begin{array}{l}\text { Não } \\
\text { datada }\end{array}$} & 10. Mecanização bibliográfica. & \\
\hline & 11. Futuro da classificação. & Não identificada \\
\hline $\begin{array}{l}\text { Não } \\
\text { datada }\end{array}$ & 12. Linguagem e outras formas de simbolismo. & $\begin{array}{l}\text { Não ofertada, mas } \\
\text { substituída pelo tema As } \\
\text { máquinas de pesquisa de } \\
\text { literatura }\end{array}$ \\
\hline \multirow[t]{3}{*}{$\begin{array}{l}\text { Não } \\
\text { datada }\end{array}$} & $\begin{array}{l}\text { 13. Reprodução de publicações - Técnicas: } \\
\text { fo tográfica e de "Near-print". }\end{array}$ & \\
\hline & 14. Preparação e edição de manuscritos. & Não identificada \\
\hline & 15. Divulgação e distribuição. & Não identificada \\
\hline \multirow[t]{2}{*}{$\begin{array}{l}\text { Não } \\
\text { datada }\end{array}$} & $\begin{array}{l}\text { 16. Problemas especiais no manuseio de outros } \\
\text { tipos de materiais para documentação - Filmes, } \\
\text { gravações, material de arquivos, tec. }\end{array}$ & \\
\hline & $\begin{array}{l}\text { 17. Problemas gerais de organização e } \\
\text { administração. }\end{array}$ & Não identificada \\
\hline Não & 18. Técnicas de avaliação - A necessidade do & \\
\hline
\end{tabular}

${ }^{9} \mathrm{Na}$ apostila é apresentado um resumo da aula do dia 14 de agosto de 1957, mas não fica claro sobre qual tema o programa pertence (Anexo B). 


\begin{tabular}{|c|l|c|}
\hline datada & desenvolvimento da pesquisa. & \\
\hline $\begin{array}{c}\text { Não } \\
\text { datada }\end{array}$ & 19. Cooperação em âmbito local e regional. & $\begin{array}{c}\text { Apresentadas no mesmo } \\
\text { dia }\end{array}$ \\
\hline $\begin{array}{c}\text { Não } \\
\text { datada }\end{array}$ & 20. Cooperação em âmbito internacional. & \\
\hline $\begin{array}{c}\text { Não } \\
\text { datada }\end{array}$ & 21. Treinamento de documentalistas. & \\
\hline
\end{tabular}

Fonte:Adaptado de Curso...(1957, p. 9) e Deão...(1957b, p. 8).

Com o objetivo de atualização de conhecimentos, teve duração de um mês, contou com 54 candidatos vindos de várias partes do Brasil; apesar da pesquisa não foi possível recuperar a lista de ouvintes, no entanto, possivelmente os alunos participantes eram provenientes dos lugares onde houve a divulgação do mesmo a partir dos periódicos, a exemplo de: Rio de Janeiro, São Paulo, bem como de outros estados onde havia escolas de biblioteconomia, como Bahia (curso fundado em 1942), Minas Gerais (curso fundado em 1950), Paraná (curso inaugurado em 1952), Pernambuco (aberto em 1950) e Rio Grande do Sul (fundado em 1947) (RUSSO, 1966).

O conteúdo transmitido pelo professor Shera foi basilar para a área, sendo importante destacar que após sua realização outros cursos de Biblioteconomia e Documentação foram instituídos no país e uma hipótese é que, participantes deste curso também tenham se deslocado para lugares, onde mais tarde foram criados cursos dessa natureza, disseminando o conhecimento apreendido e a corrente norte americana.

As aulas foram ministradas em inglês, sendo, para Fonseca (1957a, não paginado), "[..] ao mesmo tempo bonito e acessível [...]". A exigência para inscrição consistia nos seguintes critérios: ser bibliotecário formado, professor ou aluno de cursos superiores. Ao final do curso foi emitido um certificado de frequência (RUSSO, 1966). Shera já era reconhecido pelos bibliotecários brasileiros, pois as manchetes declaravam que

[...] além de excelente professor, pela influência da palavra e grande simpatia pessoal, um bibliotecário completo. Nele torna-se difícil dizer o que é maior: se a formação cultural ou profissional; e nesta, se o conhecimento teórico ou "o saber de experiências feito" louvado pelo poeta. Ele tem, ao mesmo tempo as qualidades do "bibliotecário-pedestre" e as do "bibliotecário-celeste", para usar as felizes expressões do Sr. Antônio Houaiss. (FONSECA, 1957b, não paginado). 
A documentação do curso ministrado pelo professor, obtida para esta pesquisa por meio do COMUT e disponível no repositório do MAST, foi analisada. Identificou-se que a mesma não contemplava todos os 21 tópicos do programa, faltando as preleções de ordem $11^{\circ}, 14^{\circ}, 15^{\circ}$ e $17^{\circ}$, a exposição do primeiro dia, foi apresentado um resumo e quanto ao tópico $12^{\circ}$ foi substituída pela aula intitulada "As máquinas de pesquisa de literatura", que "[...] não foi dada em aula, faz parte do programa e os dados foram fornecidos pelo Prof. Shera" (SHERA, 1957a, p. 1). Além das aulas, a apostila apresentou outras seções, como terminologia utilizada, lista de bibliografia e conferências do autor, fontes úteis sobre documentação.

Em depoimento ao Grupo de Estudos Informação Memória e Sociedade (IMES) do IBICT/RJ, Célia Ribeiro Zaher, professora do Curso de Documentação Científica do IBBD de 1954-70, declarou que "[...] bibliotecário naquela época [década de 1950] era muito malvisto [...], diziam que bibliotecário nunca sabia nada, que as bibliotecárias cuidavam dos livros, mas nunca tinham lido um livro [...]" (ZAHER, 2019). Ou seja, esses profissionais não possuíam e não buscavam o saber científico e cultural.

Algumas matérias de divulgação expressaram, em seu título, incompreensão sobre o real conteúdo e propósito do curso, do mesmo modo pode-se afirmar do fazer bibliotecário; por exemplo, os números 8.913 e 8.914 do jornal Diário Carioca (figuras 2 e 3), repetiram informações sobre o curso e estereótipos da profissão, como "guardador de livros" e "arrumador de bibliotecas". Ainda hoje, apesar de maior reconhecimento, continua o empenho da categoria pela afirmação do bibliotecário além dos muros das bibliotecas.Concomitantemente, as matérias revelam no conteúdo a importância das palestras e as renomadas instituições que estão proporcionando o evento, contudo esse ruído entre o título e texto jornalístico demonstra certa ignorância da sociedade quanto à atuação e ao alcance teórico Biblioteconomia ${ }^{10}$.

Como Oliveira (1983) comprovou em pesquisa a profissão bibliotecário sofre dupla caracterização: de um lado, intelectualizada, por outro, permeada por atividades rotineiras, monótonas e não criativas, como arrumar livros - expresso na matéria, por exemplo - porém a mesma pesquisa demonstrou que os bibliotecários rejeitam esse estereótipo. Por isso, apesar do título não fazer jus ao curso, os editores

\footnotetext{
${ }^{10}$ As informações analisadas nesta seção Curso de documentação e organização bibliográfica foram extraídas da apostila SHERA, Jesse Hauk. Curso de Documentação e organização bibliográfica. [Rio de Janeiro]: Instituto Brasileiro de Biblioteconomia e Documentação, Serviço de informações técnico-científicas, 1957. Obtida, como comentado, por meio do COMUT.
} 
acertaram ao abordar os conceitos Documentação e Organização Bibliográfica, disseminando conceitos fundamentais da Biblioteconomia, desmitificando a profissão, bem como destacando os teóricos da área e a programação para a sociedade, consequentemente, dando a conhecer mais sobre o campo e a importância da Biblioteconomia e bibliotecas para desenvolvimento social entre outros aspectos.

Figura 2- Guardador de livros

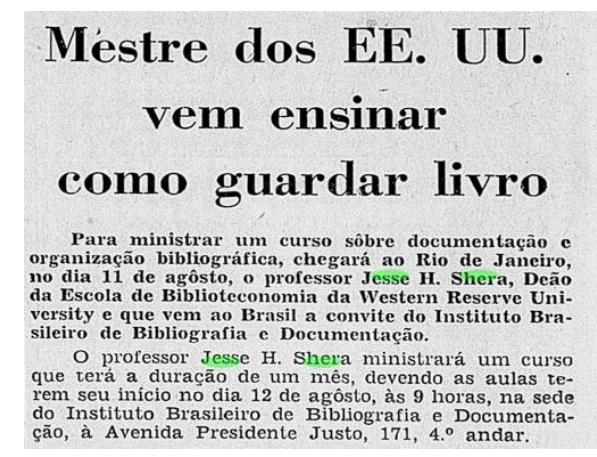

Fonte: Mestre...(1957).

Figura 3 - Fazer biblioteca

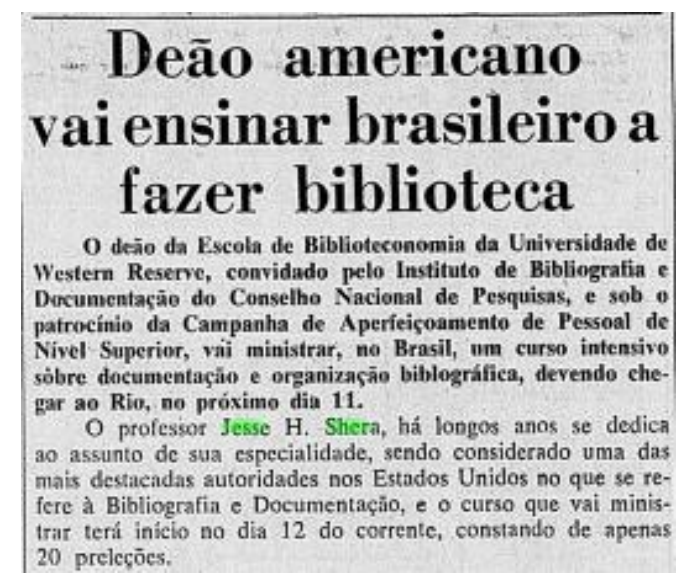

Fonte: Deão... (1957c). 
A tradução da apostila do curso foi realizada por Sônia Smilari Wiesenthal, especialista do IBBD, e, conforme reportagem do Jornal Diário da Noite (SP), assistente de Shera durante seus dias no Brasil (AINDA..., 1957). Apesar de ter ocorrido há seis décadas, o conteúdo do curso possui informações relevantes para os dias atuais, comprovando o caráter inovador para época. As bibliotecas americanas possuíam o que havia de mais moderno e as aulas tinham o intuito de renovar o conhecimento e a prática da classe em torno das recentes tecnologias e conceitos utilizados.

Shera veio ao Brasil, assim como outros convidados do IBBD, para capacitar os profissionais da informação sobre as preocupações da conjuntura do campo biblioteconômico brasileiro. O IBBD e os bibliotecários deveriam visualizar a avalanche de informação que estava sendo produzida e conhecer as técnicas desenvolvidas para a desejável organização bibliográfica. Com o padrão de desenvolvimento que o Brasil queria alcançar, o IBBD deveria ter a Documentação como produto do campo científico do país, seja na aquisição, na organização ou na disponibilização da informação.

O material inicia com uma frase enfática que foi repetida durante o curso: "A Biblioteconomia é composta de duas partes: aquisição e organização." (SHERA, 1957a, p. 1). Na primeira aula intitulada Documentação, suas finalidades e características, suas relações com os processos da comunicação de ideias e com a Biblioteconomia, Shera conceitua organização bibliográfica e documentação:

Organização bibliográfica é o trabalho de tornar acessível o material existente, enquanto que documentação é a parte da organização bibliográfica que situa e obtem o material destinado à pesquisa nos ramos da indústria, do comércio e das ciências em geral. (SHERA, 1957a, p. 1, grifos do autor).

Em entrevista ao colunista Edson Nery da Fonseca, no Jornal do Brasil (RJ), Shera declarou que "[...] Documentação é aquele aspecto da Biblioteconomia que se relaciona com a aquisição, a organização e o uso dos materiais de cultura universitária para maior benefício possível da sociedade $[\ldots]$ " (JESSE..., 1957, não paginado). Suas respostas estão segundo a orientação norte-americana, não fazendo distinção entre Documentação e Biblioteconomia Especializada, pois, apesar de terminologias diferentes, possuem "[...] o mesmo significado no mecanismo de trabalho." (SHERA, 1957a, p. 1).

Ao contrário do que acontecia nos Estados Unidos da América (EUA), a Biblioteconomia e a Documentação, segundo Shera (1957a), deveriam 
ser encaradas como um todo e não como opostas, pois ambos os profissionais das áreas têem muito o que aprender um do outro.O resumo apresentado no primeiro dia de aula destacou um breve histórico sobre a Biblioteconomia, enfatizando a Biblioteconomia Americana e uma bibliografia necessária à formação do bibliotecário. O intelectual demonstra o lado funcionalista da Biblioteconomia a partir de ideais otletianos de disseminação em todos os níveis sociais e intelectuais. (SHERA, 1957a).

O material apresenta um resumo da exposição do dia 14 de agosto de 1957, mas sem especificar o tópico ao qual fazia parte. No entanto, conforme ementa, o texto aborda

As características dos registros gráficos - a literatura de pesquisa, publicações científicas e relatórios de pesquisas científicas [...] [restringindo-se] ao tipo geralmente chamado literatura científica: 1- manuais; 2 - levantamento estatístico; 3 - livros de texto; 4 obras gerais; 5 - metodologia e finalmente; 6 - o resultado da pesquisa - o relatório de pesquisa científica. (SHERA, 1957a, p. 1).

Nessa palestra, o professor explica sobre obras de referência e a importância de conhecê-las para melhor tratá-las, pois, para um bibliotecário ser competente, ele deve conhecer as técnicas de pesquisas e as diferentes literaturas. Shera também relatou a especialização e o trabalho com peritos de outras áreas para solucionar problemas da indústria. Ele encerrou declarando que "[...] o que determinará o tratamento a ser aplicado a uma literatura de pesquisa, é a análise pormenorizada dêsse[sic] material, tendo em vista a informação a ser prestada e o tipo de leitor que esta coleção irá servir." (SHERA, 1957a, p. 4).

A explanação seguinte, apresenta os tópicos abordados no curso: 2. Forma Bibliográfica e 3. Teoria geral da bibliografia e sua relação com as práticas bibliográficas da documentação. Para Shera (1957a, p. 1, grifo do autor), "Bibliografia é um termo genérico que abrange uma variedade de tipos subordinados abstracts, indexes, ensaios bibliográficos. Cobre todos os aspectos de materiais publicados ou não."

Assim, Jesse Shera começou essa aula dissertando sobre a história, os tipos e o conceito da Bibliografia: "Prefiro encarar a bibliografia como sendo uma estrada pela qual a comunicação transita em certas direções especializadas. É um instrumento pelo qual a informação é facilitada." (SHERA, 1957a, p. 1). Nessa declaração fica claro o papel histórico e a importância da bibliografia em disponibilizar a informação tanto para o usuário, quanto para o bibliotecário na localização do material solicitado. 
No dia 19 de agosto de 1957, Shera apresentou o ponto 4. Tipos de organização bibliográficas - 0 índice, o catálogo, o abstract, o ensaio bibliográfico, em que examina mais a fundo o tema sobre as ferramentas bibliográficas. O especialista declarou que: "A Bibliografia pode ser definida como uma pirâmide cuja base é formada pelos serviços de indexação e 'abstracting'. [...] O ápice da pirâmide que representa é o ensaio bibliográfico, que é a forma mais elaborada de instrumento bibliográfico."(SHERA, 1957a, p. 1, grifos do autor).

$O$ estudo de no 5. Problemas de indexação, abstracting, e existentes na preparação de ensaios bibliográficos foi exposto no dia 20 de agosto de 1957. O professor discorreu sobre temas ainda preocupantes, referentes ao tratamento bibliográfico: "Os principais problemas de indexação, 'abstracting' e ensaios bibliográficos podem ser de diversos tipos, a saber: 1 - De profundidade; 2 - De terminologia; 3 De tipos de organização." (SHERA, 1957a, p. 1). Sobre a questão da profundidade afirmou que este é um problema fundamental da documentação e que as falhas devem ser corrigidas e não ignoradas, pois elas satisfazem as exigências básicas dos usuários.

Ao falar sobre a terminologia, explanou que esse não é um problema apenas dos bibliotecários e dos documentalistas, pois os termos devem surgir das suas próprias disciplinas. Contudo, não inibiu o trabalho com especialistas e nem a especialização em alguma área; abordou a dinâmica da língua e a dificuldade em construir índices e abstracting precisos devido à variação e variedade da língua. Para Shera (1957a, p. 3), "Igualmente quanto à organização não sabemos com segurança qual a melhor.", se o arranjo alfabético ou classificado. Como os cientistas sempre estão descontentes, Shera aconselhou fazer testes e descobrir o melhor método.

Nos dias 21 e 22 de agosto de 1957 lecionou sobre 6. Organização das publicações - classifica ção e 7. Teoria da classificação Consideração histórica. Essas aulas, assim como o ponto seguinte 8 . Sistema moderno de classificação, foram divididas em duas partes não datadas. O foco foi na história da classificação, sendo que na última aula foram discutidas as características e limitações da classificação tradicional das bibliotecas. Essas aulas sobre classificação "[...] foram particularmente apreciadas pelo auditório. Talvez porque essa matéria cujas raízes filosóficas são evidentes - nunca tenha sido apresentada, entre nós, dentro do seu interessantíssimo contexto histórico-cultural [...]." (JESSE..., 1957, não paginado).

O assunto de número 9 Outros métodos de localização e sistematização das informações, sem anotação sobre a data de realização, abordou a velocidade, a diversidade das pesquisas e a necessidade de organização e localização ocasionou 
[...] que o progresso estimulasse e suplementasse as técnicas e métodos da biblioteca tradicional.

Entre estas inovações devemos destacar os auxílios mecânicos para pesquisa de literatura, variando do cartão perfurado de seleção manual até o equipamento mais específico, no gênero dos computadores. (SHERA, 1957a, p. 1).

A partir disso, comentou sobre os novos sistemas mecânicos de reobtenção de informações, termo utilizado por ele durante o curso para denominar as tecnologias de recuperação da informação. A aquisição desses mecanismos é justificável pela economia e rapidez da resposta dada pelo sistema, o qual enfatiza os requisitos para pesquisa, como números, assunto ou campos restritos. É um tópico interessante, pois, apesar de seis décadas e de instrumentos ainda rudimentares comparados com modernos computadores e softwares atuais, é possível identificar semelhanças e desafios para a exaustividade e precisão na recuperação, como a indexação e a rapidez das respostas do sistema.

O professor também foi um desenvolvedor de aparatos tecnológicos, tendo muito o que ensinar. Conforme o jornal Diário da Noite:

O professor Shera com uma equipe de que faziam parte ainda os documentalistas James $\mathrm{W}$. Perry e Allen Kent e com o auxílio dos estudantes da faculdade de que é deão, construiu uma máquina eletrônica, espécie de "cérebro". Devidamente "programada" essa máquina através de perfuração de cartões e com um simples apertar de um botão, fornece de imediato toda uma relação de publicações e material vario sobre cada determinada especialidade [...] (AINDA..., 1957, p. 12).

O título do ponto 10 foi Mecanização bibliográfica. Como ele afirmou, não se pretendia apresentar todos os processos mecânicos existentes, mas sim estudar os mais típicos para se visualizar o estado atual dos métodos mecanizados (SHERA, 1957a). Shera comentou sobre o sistema de cartões de margens perfuradas (Edge: notched cards); os cartões perfurados de seleção pelas máquinas I.B.M. e Remington Rand; o método Peek-a-Boo, invenções que usam filmes fotográficos; computadores eletrônicos; a máquina selecionadora e pesquisadora da Western Reserve University (WRU Searching Selector). Na opinião do professor, "Ainda há muito o que fazer para aperfeiçoar as máquinas, mas elas representam uma grande promessa para o futuro e podem, dentro de cinco ou dez anos, revolucionar a biblioteconomia e a documentação." (JESSE..., 1957, não paginado). 
O tópico 12 Linguagem e outras formas de simbolismo não foi apresentado no material, porém foi entregue uma matéria pelo professor Shera, cuja nota de rodapé afirmava que o texto fazia parte do programa. Nesse texto, intitulado As máquinas de pesquisa de literatura, o professor explanava sobre as máquinas para pesquisa de literatura ou máquinas, como ele mencionou, destinadas à reobtenção de informações. Foi uma aula básica de automação, apesar da palavra não ter ficado evidente. O docente abordou as necessidades das máquinas e suas linguagens.

É muito importante que o homem se deixe levar pelo entusiasmo em relação à máquina. Até o presente tem sido prolongamentos mecânicos do homem; elas não são capazes de realizar um trabalho cerebral. É possível que no futuro a máquina se torne um prolongamento do cérebro. Mesmo assim será difícil acreditar que as máquinas poderão realizar o raciocínio que o cérebro humano executa. (SHERA, 1957a, p.1).

Na preleção de ordem 13 Reprodução de publicações Técnicas: fotográfica e de Near-print, Shera discursou sobre técnicas de impressão, citando: near-print, ectograph, mimeografo, multilith, técnicas de fotografias, sistemas fotostáticos e de microfilme, photon, técnicas modernas à época e outras não adequadas, como stencil e adressograph ${ }^{11}$. As informações foram de muito proveito para os alunos, pois, como o professor afirmou:

\footnotetext{
${ }^{11}$ Near-print: "[...] um processo de duplicação que se assemelha a impressão tipográfica [...] mas não envolve a configuração do tipo de metal [...]". Disponível em: https://translate.google.com/translate?hl=pt-BR\&sl=en\&u=https://www .merriamwebster.com/dictionary/near-print\&prev=search. Acessado em: 20 out. 2019. Ectograph: "[...]é uma impressão de processo que envolve a transferência de um original, preparado com tinta especial, para uma panela de gelatina ou de uma camada de gelatina bem apertada sobre uma armação de metal". Disponível em: https://pt.qwertyu.wiki/wiki/Hectograph. Acesso em: 20 out. 2019. Mimeografo: "Aparelho impressor que reproduz desenhos ou letras perfuradas numa matriz de papel especial, chamada estêncil". Disponível em: https://www.dicio.com.br/mimeografo/. Acesso 20 out. 2019. Microfilme: "A microfilmagem é um método de gerenciar e armazenar informações através da captação de imagens dos documentos por um processo fotográfico". Disponível em: https://netscandigital.com/blog/o que-e-microfilmagem/. Acesso em: 20 out. 2019. Stencil: "A serigrafia foi criada através da evolução de uma técnica de impressão chamada "estêncil" onde criamos uma máscara vazada com o desenho em uma superfície rígida e com a aplicação de tinta sobre esse molde é feita a impressão". Disponível em: https://cursodesilkscreen.com.br/serigrafia-ou-silk-screen/. Acesso em: 20 out. 2019. Foram escassas fontes sobre as demais técnicas citadas.
} 
[...] os Estados Unidos, devido à grande força dos sindicatos de topógrafos, conseguem manter um alto custo para impressão e uma constante busca de novas técnicas, creio que no Brasil o mesmo não acontece [...]. Creio que o mais prático, no caso do IBBD, é continuar empregando os métodos tradicionais. (SHERA, 1957a, p. 2).

No Brasil, as unidades de informação careciam de recursos materiais e financeiros para organizar, disponibilizar e guardar os seus acervos, como em alguns centros de informação ainda persistem estas dificuldades. O item seguinte 16. Problemas especiais no manuse io de outros tipos de materiais para documentação - Filmes, gravações, material de arquivo, etc., orientou os bibliotecários sobre o manuseio e conservação dos diferentes e novos materiais,como microfilmes, gravações, microfichas.

O preletor explicou sobre o tratamento dispensado a esses materiais, a ausência de guias, o que faz os documentalistas desenvolverem suas próprias técnicas, considerando "Êste campo [...] ainda é uma grande floresta a ser explorada [...]" (SHERA, 1957a, p. 1). Shera concluiu que uma das maneiras de resolver o problema era fazer bibliografias e se manter informado sobre tudo o que aparece no mercado para auxílio na manipulação desses materiais (SHERA, 1957a).

O ponto 18 Técnicas de avaliação - A necessidade do desenvolvimento da pesquisa tratou sobre a avaliação dos serviços das bibliotecas, com foco na indústria e comércio, a fim de atender às necessidades do capital. A avaliação não considerou apenas a sua implementação, que deve priorizar valores tangíveis e intangíveis, mas a sua permanência. Shera defendia que a avaliação é uma etapa importante do planejamento e da organização de uma biblioteca, pois otimiza recursos e realiza melhorias nos serviços de informação, pois "Creio ser de nosso dever facilitar a tarefa do documentalista; muitas vezes [sic] um centro de documentação desperdiça energias fazendo serviços desnecessários, seguindo uma rotina tradicional de trabalho e não procura verificar se tais trabalhos são necessários." (SHERA, 1957a, p.3).

Os temas 19. Cooperação em âmbito local e regional e 20. Cooperação em âmbito internacional, possivelmente foram apresentados no mesmo dia, conforme organização da fonte primária. Shera, ao explicar sobre a cooperação entre bibliotecas e bibliotecários, enfatizou que "Devemos principalmente incrementar a cooperação entre bibliotecários, documentalistas e a indústria e pesquisa." (SHERA, 1957a, p. 1). O especialista também afirmou que a publicação é uma das formas de cooperação e que a Western Reserve University, atual Case Western 
Reserve University ${ }^{12}$, universidade onde era Deão, estaria aberta para receber trabalhos.

O docente comparou o Brasil e os EUA em termos de cooperação, elogiando o desempenho do IBBD. Para ele, o "[...] IBBD em pouco tempo, com poucos recursos já realizou um trabalho importante e o Conselho Nacional de Pesquisas deve compreender a importância do IBBD. Nos Estados Unidos não existe nenhum serviço do gênero do IBBD." (SHERA, 1957a, p. 2).

Da mesma maneira que incentivou o trabalho com outros especialistas para elaboração de índices, Shera afirmou que

O sêr humano tem a tendência de realizar um trabalho individual e deve ser forçado a trabalhar em conjunto, necessita uma pressão extrema neste sentido.

Os novos problemas de grande importância forçarão esta cooperação e somente assim poderemos realmente progredir. (SHERA, 1957a, p.3).

A última explanação foi o ponto 21 do programa, intitulado Treinamento de documentalistas. Inicialmente, o professor explicou sobre a construção da educação formal da Biblioteconomia dos EUA, ressaltando os trabalhos de Dr. Wilson Deão, da Universidade de Chicago, que acreditava, assim como Shera, que "[...] a biblioteca é uma instituição social e, portanto, os bibliotecários deviam ter uma base sólida em ciências sociais [...]" (SHERA, 1957a, p. 2).

O intelectual foi estudioso de Sociologia e das questões sociais, por isso, para ele, a "Biblioteconomia é uma agência de comunicação para a sociedade, para a distribuição de informações precisas, de leitura recreativa, atividades diversas, deve ser uma ponte, entre os registros gráficos através do indivíduo para a sociedade." (SHERA, 1957a, p.3).

O educador não era contra a técnica, mas afirmou que ela era uma restrição para a verdadeira estrada da Biblioteconomia, que seria baseada na Filosofia e na Epistemologia Social, tendo o documentalista uma cultura sólida e geral. Não ignorava a especialização, pois, como a Biblioteconomia era formada essencialmente pela aquisição e organização, ele considerava que "Para que o bibliotecário seja realmente habil [sic]na aquisição, êle[sic]deve se especializar em determinado assunto." (SHERA, 1957a, p. 4). Contudo,

\footnotetext{
${ }^{12}$ Universidade privada dos Estados Unidos, localizada em Cleveland, no estado de Ohio.
} 
Como base cultural creio que o bibliotecário necessita:

1- Conhecimento geral de todas as disciplinas, sociologia, filosofia, história etc.

2- Especialização em algum destes assuntos.

3 - Conhecimento de biblioteconomia, suas relações com outros ramos da ciência. (SHERA, 1957a, p. 4).

Jesse Shera, mais uma vez, chamou a atenção para a integração e o diálogo entre a Biblioteconomia e outras áreas do conhecimento.

O importante é saber como usar uma técnica e transferi-la a sistemas diferentes. Quem, por exemplo, conhece a estrutura do esquema de Dewey pode transferir esse conhecimento de estrutura, a qualquer outro esquema ou memorizar esse conhecimento como base para criação de novos esquemas. (SHERA, 1957a, p. 5).

Igualmente, esclareceu não defender hierarquias na Biblioteconomia, mesmo em relação à Documentação, mas um trabalho em conjunto com foco nas necessidades dos usuários, uma vez que,

[...] Da mesma maneira devemos encarar a biblioteconomia como uma unidade e o relacionamento da documentação com a clientela; é este relacionamento básico que precisamos conhecer. Teremos menos conflitos entre bibliotecários e documentalistas se compreendermos melhor esta necessidade. É preciso não pensarmos em têrmos [sic]de hierarquia dentro da carreira; uma bibliotecária infantil é também uma especialista com a vantagem de conhecer mais de perto a sua clientela. (SHERA, 1957a, p.5).

O curso incluiu aulas de conteúdo histórico e conceitual, mas foi predominantemente voltado à técnica, instrumentos, aquisição e organização de novos materiais. O professor durante todo o curso, contrapôs a documentação americana à brasileira, recorrendo à primeira como base para explicação. Suas exposições estavam direcionadas à especialização e ao atendimento da indústria e comércio, sem desconsiderar o conhecimento da Biblioteconomia em diferentes atuações e o trabalho em conjunto com outros profissionais. Como ele declarou, a Biblioteconomia deveria recuar até a Antropologia, a Comunicação, as linguagens e a organização social para compreender de que maneira a sociedade arquivava o conhecimento (SHERA, 1957a).

Em 1957, ano da realização do curso de Documentação e Organização Bibliográfica, o Brasil estava em uma corrida ao progresso 
econômico e desenvolvimentista. O governo Juscelino Kubistchek ${ }^{13}$ e seu Plano de Metas 50 anos em 5

[...] indicavam a necessidade de eliminar os "pontos de estrangulamento" da economia brasileira. Tratava-se de setores críticos que não permitiam um adequado funcionamento da economia. A premissa do Plano de Metas, esboçado pouco antes da posse de JK por uma equipe do BNDE, era, assim, a superação desses obstáculos estruturais [...] (FUNDAÇÃO GETULIO VARGAS, 2019, não paginado).

Os setores que mais receberam recursos foram energia, transporte e indústria de base, contudo o objetivo do Plano era incentivar mudanças de maneira harmoniosa e em cadeia. Por esse motivo, a documentação também foi incluída nesse projeto. O IBBD já estava como modelo de Biblioteconomia dentro e fora do país e deveria acompanhar as propostas governamentais, destacando o papel do bibliotecário e do documentalista na ciência e no crescimento do país(ODDONE, 2006; SILVA, 1957).

$\mathrm{Na}$ edição do jornal Correio Paulistano do dia 30 de outubro de 1957, Afrânio Coutinho, professor, crítico literário e ensaísta brasileiro, denunciou a carência da organização e disponibilização bibliográfica da produção intelectual do país. Atenção que também foi suscitada no curso de Documentação e Organização Bibliográfica e destacada na matéria pelo redator:

Nossa falta de consciência bibliográfica parece denotar que não temos ainda, no Brasil, verdadeira noção do que é a organização da cultura e quais os instrumentos que a fazem funcionar. A todo momento, ainda hoje, vemos intelectuais reclamarem contra a apresentação de bibliografia e de referencias em obras de erudição [...] Mas não é em vão que está crescendo, tomando corpo, consistência e conteúdo, dia a dia, em nível universitário, a ciência da documentação, cuja problemática foi posta em foco recentemente com a visita e as conferencias do notável professor Jesse $\mathrm{H}$. Shera, uma das maiores autoridades mundia is na matéria. (COUTINHO, 1957, p. 6).

Este empasse ainda se manteria, pois, em edição do Correio da Manhã de 9 de setembro de 1958, noticiou-se que

13 Presidente da República durante 1956-1961. 
[...] O Brasil, contando com 2 milhões de volumes da Biblioteca Nacional, a maior do país e uma das mais importante da América do Sul, retém tão somente 3 milhões do que até hoje produziu o homem nos diferentes campos da cultura. Por aí se vê que em matéria de documentação, fator imprescindível no progresso de uma nação, o Brasil apenas engatilha, apesar de já contar com uma organização especializada. (BRASIL..., 1958, p. 2).

O IBBD era a organização especializada citada que estimulava e organizava[...]a execução de trabalhos bibliográficos empreendidos pelas diferentes instituições especializadas e quando solicitado, participava ativamente desses trabalhos, auxiliando, colaborando ativamente, sempre evitando qualquer duplicação de serviço. Outra colaboração do instituto apontada no artigo foram os "[...] Cursos avançados de biblioteconomia são dados regularmente. Ainda no ano passado, aqui esteve o Prof. Jesse Shera, renomado documentalista dos Estados Unidos. " (BRASIL..., 1958, p. 2). A alusão nesse editorial a Jesse Shera e ao curso intensivo, mais uma vez, não foi aleatória, mas justificável. O curso ministrado e a presença de Shera trouxe incentivos à classe bibliotecária na capacitação, atualização e organização do conhecimento, técnica e informação à sociedade.

Um curso técnico com a essência social de Shera era o que o IBBD tanto precisava para responder às inquietações do governo, dos pesquisadores e dos bibliotecários alheios a esse conhecimento. O campo biblioteconômico estava adquirindo realce e mais forma, ou corpo, como explanou Afrânio Coutinho no periódico Correio Paulistano (COUTINHO, 1957).

$\mathrm{Na}$ "[...] época das bibliotecas especializadas [...]" (FONSECA, 1957c, p. 3), esse intelectual trouxe o olhar americano social e da técnica para que os bibliotecários despertassem a atenção dos pesquisadores e autoridades sobre a importância do bibliotecário e documentalista nas empresas.

[...] Nos Estados Unidos, uma empresa industrial que se encontrava em fase de organização, dispendeu a importância 100.000 dollars com execução de trabalhos de pesquisa para a escolha do local mais adequado ao seu funcionamento. Finda a tarefa, surpreendentemente, constataram, os diretores da empresa que, com o auxílio de um bibliotecário eficiente, técnico em documentação, poderiam ter obtido a bibliografia e todo material indispensável, às pesquisas que, nesse caso custariam 75 cento menos, aproximadamente, do que aquele total despendido (AINDA..., 1957, p. 12). 
Os benefícios da biblioteconomia americana seriam notados, pois, na edição 210 de 1958 do Diário de Pernambuco, Edson Nery da Fonseca declarou

Aos primeiros bibliotecários brasileiros formados nos Estados Unidos deve-se a transformação por que passaram as nossas bibliotecas, a partir de 1930. O livre acesso às estantes, o empréstimo domiciliar e outras vantagens proporcionadas pela biblioteconomia moderna resultaram de uma nova e salutar mentalidade: a de que as bibliotecas existem menos para conservar do que para difundir os livros [...] (FONSECA, 1958b, p. 1).

Portanto, entre as contribuições do professor Jesse Hauk Shera estão a participação e promoção de melhorias a partir da transmissão de informação sobre novas técnicas e métodos de organização e aquisição. Baseado em ideais americanos e otletianos, defendeu e estimulou a perspectiva de que o bibliotecário não é um mero servo, independente ou alheio à ciência e à sociedade, mas um transformador social e difusor do conhecimento.

\section{Conclusão}

A partir da sua atuação na Biblioteconomia brasileira Shera impulsionou a categoria a atualização de conhecimentos, a mudanças de práticas e modernização das unidades de informação. Suas ideias foram refletidas e aplicadas pelo IBBD, organização modelo para as demais instituições de informação no país, ocasionando maior absorção da corrente americana e de seus princípios pelas demais organizações e bibliotecários pelo Brasil.

Por conseguinte, no Brasil, a Biblioteconomia incorporou, mais fortemente, o tecnicismo americano. Nota-se, por exemplo, a importância dada por este teórico ao processo de interdisciplinaridade entre as ciências, da mesma forma em que ele chama a atenção para a importância da aproximação com as tecnologias emergentes em meados do século XX. Aspectos que os profissionais foram alertados a se concentrarem pelas transformações que estavam surgindo; assim capazes de atender as exigências e necessidades governamentais e empresariais, foco este do IBBD e racionalizada por demais entidades informacionais, sem se distancia do aspecto ou função social, como Shera muito bem destacou.

No âmbito educacional e profissional, o curso ministrado e as intervenções deste teórico instigaram os bibliotecários a questionarem seus métodos, em classificação, localização de materiais, reprodução, 
automação, principalmente. Seu discurso fez repensar o significado da Biblioteconomia e o perfil do profissional, ampliando a atuação deste com a abordagem Documental, no manuseio de outros suportes a informação, diferente do tradicional papel, bem como no aprimoramento da indexação.

Institucionalmente, sua atuação foi de elogios à organização e produção bibliografia do país, principalmente referentes às pesquisas científicas desenvolvidas; estimulou a cooperação internacional, modernização das bibliotecas e trabalhos em conjunto com diferentes especialistas para uma visão do todo e não apenas parcial. Porém, ainda foram observadas lacunas na estruturação da informação brasileira gerando, com isso, reflexões sobre a organização bibliográfica do país.

Associando a instrução teórica com o ensinamento prático,esse intelectual conseguiu promover reflexões no ensino e no desempenho de bibliotecários,como também na estrutura informacional do país, sucedendo diálogos sobre a organização bibliográfica brasileira, o que implica em mudanças conceituais e educacionais, bem como no propósito dos órgãos de informação no Brasil.

Portanto, Shera foi um pioneiro que teve impacto no pensamento bibliotecário brasileiro para uma ciência norteada por concepções da corrente americana, sem negligenciar os ideais de disseminação da informação otletianos. Fundamentou o discurso e consequentemente a prática biblioteconômica, na formação de futuros profissionais e na postura institucional do país, destacando a Biblioteconomia como ciência local e mundialmente.

Desta maneira, contribui para que esta ciência adquirisse forma e visibilidade por parte de governos e organização profissional enquanto classe para melhor atuação e condições de trabalho adequadas. Sua teoria ainda muito tem a oferecer para atualização da teoria e prática bibliotecária. Seu curso discorreu sobre temas ainda pertinentes e sua produção bibliográfica é multi e interdisciplinar, aberta a observações, assim como o professor durante sua carreira acadêmica e profissional.

\section{Referências}

AINDA pouco compreendida a importância do papel dos técnicos em documentação. Diário da Noite, São Paulo, ano 32, n. 10004, p. 12, 9 set. 1957. Disponível em: http://memoria.bn.br/hdb/periodico.aspx. Acesso em: 24 ago. 2019.

BOURDIEU, Pierre. Questões de Sociologia. Rio de Janeiro: Marco Zero, 1983.

BRASIL tem só 3 dos 25 milhões de obras publicadas des de o advento da imprensa. Correio da Manhã, Rio de Janeiro, a. 58, n. 20078, p. 2, 9 set. 
1958. Disponível em: http://memoria.bn.br/hdb/periodico.aspx. Acesso em: 24 ago. 2019.

BRASIL. Presidência da República. Casa Civil. Decreto no 35.430, de 29 de abril de 1954. Aprova o Regimento do Instituto Brasileiro de Bibliografia a e Documentação (I. B. B. D.). Brasília, DF: Presidência da República, 1954b. Disponível em:

https://www2.camara.leg.br/legin/fed/decret/1950-1959/decreto-3543029-abril-1954-326567-publicacaooriginal-1-pe.html. Acesso em: 4 mar. 2019.

CASTRO, César. História da biblioteconomia brasileira: perspectiva histórica. Brasília, DF: Thesaurus, 2000.

CHEGARÁ no dia 11 o deão da Western Reserve University. Diário de Notícias, Rio de Janeiro, ano 28, n. 10658, p. 4, 9 ago. 1957. Disponível em: http://memoria.bn.br/hdb/periodico.aspx. Acesso em: 24 ago. 2019.

COUTINHO, Afrânio. A organização da cultura. Correio Paulistano, São Paulo, ano 104, n. 31.161, p. 6, 30 out. 1957. Disponível em: http://memoria.bn.br/hdb/periodico.aspx. Acesso em: 24 ago. 2019.

CURSO intensivo de biblioteconomia. Jornal do Brasil, Rio de Janeiro, ano 67, n. 178, p. 9, 3 ago. 1957. Disponível em: http://memoria.bn.br/hdb/periodico.aspx. Acesso em: 24 ago. 2019.

DEÃO americano chegará amanhã. Jornal do Commercio, Rio de Janeiro, n. 260, 10 ago. 1957a. Disponível em: http://memoria.bn.br/DocReader/docreader.aspx?bib $=364568$ 14\&pasta =ano\%20195\&pesq=Jesse\%20Shera. Acesso em: 05 jan. 2020.

DEÃO vem ensinar como se faz documentação. Última Hora, Rio de Janeiro, ano 7, n. 2. 176, p. 8, 3 ago. 1957b. Disponível em: https://www.google.com/search?client=firefox-bd\&channel=crow5\&sXsif=AOaemvK85EIQ190Q7vUb6XiLyX6irJYLhQ: 16313 14165229\&q=http://memoria.bn.br/DocReader/docreader.aspx?bib\%3D3 86030\%26pasta\%3Dano\%2520195+pesq\%3DJesse\%2520+She+Ra\&spel

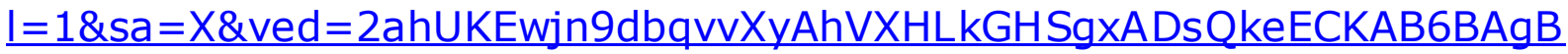
ED0. Acesso em: 05 jan. 2020.

DEÃO americano vai ensinar brasileiro a fazer biblioteca. Diário Carioca, Rio de Janeiro, ano 30, n. 8.914, 4-5 ago. 1957c. Disponível em: http://memoria.bn.br/DocReader/docreader.aspx?bib=093092 04\&pasta =ano\%20195\&pesq=Jesse\%20Shera. Acesso em: 05 jan. 2020. 
DEMO, Pedro. Metodologia do conhecimento científico. São Paulo: Atlas, 2000.

FONSECA, Edson Nery da. A biblioteconomia brasileira no contexto mundial. Rio de Janeiro: Tempo Brasileiro; Brasília, DF: INL, 1979.

FONSECA, Edson Nery da. Jesse H. Shera. Jornal do Brasil. Rio de Janeiro, 25 ago. 1957a. Disponível em: http://memoria.bn.br/hdb/periodo.aspx. Acesso em: 29 ago. 2018.

FONSECA, Edson Nery da. Desenvolvimento da Biblioteconomia e da Bibliografia no Brasil. Revista do Livro, ano 2, n. 5, p. 95-124, mar. 1957b. Disponível em:

http://memoria.bn.br/DocReader/docreader.aspx?bib=393541\&pasta =ano \%20195\&pesq=. Acesso em: 24 mar. 2019.

FONSECA, Edson Nery da. Bibliotecas especializadas e catálogos coletivos: independência ou morte. Tribuna da Imprensa, Rio de Janeiro, ano 9, n. 2376, p. 3, 26-27 out. 1957c. Disponível em: http://memoria.bn.br/hdb/periodico.aspx. Acesso em: 24 ago. 2019.

FONSECA, Edson Nery da. Bibliografia, biblioteconomia e Documentação. A Biblioteca, Rio de Janeiro, n. 10, p. 6, jul./dez. 1958a. Disponível em: http://memoria.bn.br/DocReader/docreader.aspx?bib=068306\&pasta =ano \%20195\&pesq=Jesse\%20Shera. Acesso em: 24 ago. 2019.

FONSECA, Edson Nery da. Epitáfio para uma classificação morta. Diário de Pernambuco, Recife, ano 133, n. 210, p. 1, 14 set. 1958b. Disponível em: http://memoria.bn.br/hdb/periodico.aspx. Acesso em: 24 ago. 2019.

FUNDAÇÃO GETULIO VARGAS. Centro de Pesquisa e Documentação de História Contemporânea do Brasil. O Brasil de JK: 50 anos em 5: o plano de metas. Rio de Janeiro: CPDOC/FGV. Disponível em: https://cpdoc.fgv.br/producao/dossies/JK/artigos/Economia/PlanodeMetas - Acesso em: 23 set. 2019.

JESSE Shera: dentro cinco ou dez anos as máquinas podem revolucionar a biblioteconomia e a documentação. Jornal do Brasil, Rio de Janeiro, ano 67, n. 203, 1 set. 1957. Disponível em:

http://memoria.bn.br/hdb/periodico.aspx. Acesso em: 24 ago. 2019.

JUVÊNCIO, CARLOS HENRIQUE. Manoel Cícero Peregrino da Silva, a Biblioteca Nacional e as origens da Documentação no Brasil. 2016. 216 f. Tese (Doutorado em Ciência da Informação) - Faculdade de Ciência da Informação, Universidade de Brasília, Brasília, 2016. 
LIMA, Raimundo Martins de. A construção social da biblioteconomia brasileira. Manaus: Ed. da Universidade do Amazonas, 1999.

MESTRE dos EE. UU. vem ensinar como guardar livros. Diário Carioca, Rio de janeiro, ano 30, n. 8.913, 3 ago. 1957. Disponível em:

http://memoria.bn.br/DocReader/docreader.aspx?bib=093092 04\&pasta =ano\%20195\&pesq=Jesse\%20Shera. Acesso em: 05 jan. 2020.

MORAES, Rubens Borba de. A lição das bibliotecas americanas. Revista do Arquivo Municipal, São Paulo, ano 7, v. 84, p. 197-208, jul./ago. 1942. Disponível em:

https://www.prefeitura.sp.gov.br/cidade/secretarias/cultura/arquivo histo rico/publicacoes/index.php?p=8312. Acesso em: 24 ago. 2019.

MORAES, Rubens Borba de. O problema das bibliotecas brasileiras. Rio de Janeiro: Casa do Estudante do Brasil, 1943.

MOURA, Washington José de Almeida. A propósito da vinda do professor Shera ao Brasil. IBBD Boletim Informativo, Rio de Janeiro, v. 3, n. 3-4, p. 165-168, maio/ago. 1957.

O DEÃO da Western Reserve University realizará um curso nesta capital. $A$ Noite, Rio de Janeiro, ano 46, n. 15. 686, p. 2, 3 ago. 1957. Disponível em:

http://memoria.bn.br/DocReader/docreader.aspx?bib=348970 05\&pasta =ano\%20195\&pesq=Jesse\%20Shera. Acesso em: 1 nov. 2019.

ODDONE, Nanci Elizabeth. O IBBD e a informação científica: uma perspectiva histórica para a ciência da informação no Brasil. Ci. Inf., Brasília, v. 35, n. 1, p. 45-56, jan./abr. 2006. Disponível em:

file://C:/Users/055744501180/Downloads/1152-1707-1-PB\%20(1).pdf. Acesso em: 29 ago. 2018.

OLIVEIRA, Zita Catarina Prates de. O bibliotecário e sua auto-imagem. São Paulo: Pioneira, 1983.

RUSSO, Laura Garcia Moreno. A biblioteconomia brasileira 1915 - 1965. Rio de Janeiro: Instituto nacional do livro, 1966.

SAMBAQUY, Lydia de Queiroz. O IBBD e a informação científica no Brasil. Fórum educ., Rio de Janeiro, v. 12, n. 2, p. 31-41, abr./jun. 1988. Disponível em: file://C:/Users/m/Downloads/61002-128372-1PB\%20(1).pdf. Acesso em: 24 mar. 2019. 
SANT'ANNA, Vanya M. Ciência e sociedade no Brasil. São Paulo: Símbolo, 1978.

SHERA, Jesse Hauk. Curso de Documentação e organização bibliográfica. [Rio de Janeiro]: Instituto Brasileiro de Biblioteconomia e Documentação, Serviço de informações técnico-científicas, 1957a.

ZAHER, Celia. Celia Zaher: entrevista ao IMeS/IBICT. [Entrevista cedida ao] Grupo de Pesquisa Informação, Memória e Sociedade. IMeS IBICT, 7 mar. 2017. Disponível em:

https://www.youtube.com/watch? $v=$ fW kowQSoyW M\&list $=W L \& i n d e x=2 \& t$ $\equiv 2059$ s. Acesso em: 23 set. 2019. 